\title{
Hypothesis Proposal about Predictive Factors and Optimal Age for Response to Herbal Medicine Treatment for Height Gain in Children: a Retrospective Review
}

\author{
Jungtae Leem ${ }^{1,2,3}$, Jeeyeun $\mathrm{Kim}^{4}$, Kyeungsuk $\mathrm{Suh}^{4}$, Youngkwern $\mathrm{Lim}^{4 *}$, Junhee Lee ${ }^{3,5^{*}}$ \\ ${ }^{1}$ Department of Internal Medicine of Korean Medicine, Dongshin Korean Medicine Hospital, 351, Omok-ro, \\ Yangcheon-gu, Seoul, 07999, Republic of Korea \\ ${ }^{2}$ Chung-Yeon Medical Institute, 64, Sangmujungang-ro, Seo-gu, Gwangju, 61949, Republic of Korea \\ ${ }^{3}$ Korean Medicine Clinical Trial Center, Kyung Hee University Korean Medicine Hospital, 23 Kyungheedae-ro, \\ Dongdaemun-gu, Seoul, 02447, South Korea \\ ${ }^{4}$ Aijoafamily Korean Medical Clinic Network, 1587 Bongyeong-ro, Yeongtong-gu, Suwon-si Gyeonggi-do, 16703, South Korea \\ ${ }^{5}$ Department of Sasang Constitutional Medicine, College of Korean Medicine, Kyung Hee University, 26 \\ Kyungheedae-ro, Dongdaemun-gu, Seoul, 02447, South Korea
}

\begin{abstract}
Introduction: We aimed to investigate the predictive factors and optimal age for response to herbal medicine treatment for height gain in children.

Methods: This retrospective chart review included 61 children (age range, 5-16 years) treated for height gain between 2011 and 2015. A predictive model was established by multiple linear regression analysis. Dependent variables were defined by the differences in percentile before and after herbal medicine treatment. The optimal cutoff value of patient age was determined by receiver operating curve analysis.

Results : The age of initiation of herbal medicine therapy $(\mathrm{p}=0.012)$ and administration of Forsythiae fructus $(\mathrm{p}=0.002)$ were significant variables for treatment response. The adjusted R2 value was 0.231 . The mean ages of the responder and non-responder groups were significantly different $(p=0.023)$. The optimal cutoff value of age for predicting treatment response was 9.75 years. Treatment response was better among children below 9.75 years of age.

Conclusions: Patient age and administration of Forsythiae fructus were identified as determinants of response to herbal medicine treatment. Treatment of rhinitis and initiation of height gain treatment at an early age are critical for better response. These findings will provide fundamental data for further research.
\end{abstract}

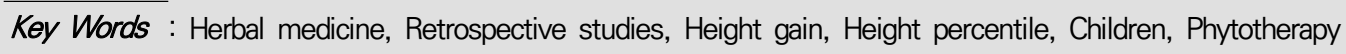

\section{Introduction}

Idiopathic short stature (ISS) is defined by a height less than 2.0 standard deviation (SD) of the average height of the corresponding population in the absence of any other disease that could explain the short stature ${ }^{1)}$.

\footnotetext{
- Received : 6 February 2018 • Revised : 19 April $2018 \quad \cdot$ Accepted : 2 May 2018

- Correspondence to : Junhee Lee

Department of Sasang Constitutional Medicine, College of Korean Medicine, Kyung Hee University, 26 Kyungheedae-ro, Dongdaemun-gu, Seoul, 02447, South Korea

Tel : +82-2-958-9280 E-mail : ssljh@khu.ac.kr

- Correspondence to : Youngkwern Lim

Aijoa Korean Medical Clinic Network,1587 Bongyeong-ro, Yeongtong-gu, Suwon-si Gyeonggi-do, 16703, South Korea Tel : +82-31-273-3375, E-mail : kinddoctor@hanmail.net
} 
The fact that $80 \%$ of short children who visit pediatric clinics are diagnosed with ISS indicates that most children of short stature exhibit no pathological findings or history of low birth weight and/or height ${ }^{1}$. The Food and Drug Administration approved growth hormone (GH) therapy for patients with ISS with height less than $2.25 \mathrm{SD}$ (1.2 percentile) of the corresponding population $^{2}$. Although GH therapy has been known to increase height in adults by up to $4 \mathrm{~cm}^{2}$, several side effects of treatment have been reported, including intracranial hypertension, edema, worsening of scoliosis, and hyperglycemia ${ }^{3), 4)}$.

Herbal medicine is a widely used intervention for height gain in children in Korea. According to a previous study, 4.4-7.3\% of school-children attempt treatment for height gain, and herbal medicine is the most commonly administered treatment modality ${ }^{5}$. Several clinical studies have reported the positive effects of herbal medicine on height gain ${ }^{6-9)}$. In addition, the side effects of herbal medicine in children are relatively few and not serious. In a previous study, only $4.2 \%$ of the children exhibited side effects, most of which disappeared spontaneously ${ }^{10)}$. Another study reported that most parents (89\%) expected that Korean medicine (KM) therapy would increase the rate of height gain and believed herbal medicine to be the most important treatment modality for the same ${ }^{11)}$. Satisfaction with the outcome of herbal medicine treatment was also reported to be high (62\%), and $52 \%$ of parents were reported as believing $\mathrm{KM}$ treatment to be better than western medicine ${ }^{12)}$.

Several factors, including the initiation of GH therapy in the prepubescent period, delay in bone aging, and dosage of $\mathrm{GH}$, can predict the outcome of $\mathrm{GH}$ therapy ${ }^{2), 13)}$. Patient age, weight, midparental height (MPH), GH dosage, and response to GH treatment in standard provocation tests were reported as being important determinants for treatment outcome in a statistical model study ${ }^{14)}$. However, most patients who present at KM clinics for treatment for height gain do not satisfy the criteria for ISS diagnosis. In a previous report, only $12.1 \%$ of the patients were reported as being shorter than the $3^{\text {rd }}$ percentile ${ }^{15)}$, which indicates that patients who prefer herbal medicine treatment do not often satisfy the indication criteria for GH therapy. Therefore, application of predictive factors for treatment response in western medicine therapy to KM without evaluation is not reasonable. The determinants for treatment response have not yet been established in herbal medicine treatment. Therefore, in this study, we attempted to determine the factors that could predict treatment response with herbal medicine for height gain in children by multiple linear regression analysis with adjustment for confounding factors. Additionally, we also attempted to determine the optimum cutoff value of the continuous variable by receiver operating characteristic (ROC) curve analysis.

\section{Methods}

\section{Subjects}

We conducted a retrospective chart review of children who visited the Suwon Aijoa KM clinic located in Suwon, South Korea for treatment for height gain between January 2011 and April 2015. The Kyung Hee University Korean Medicine Hospital institutional review board (IRB) approved this retrospective observational study (KOMCIRB-160219-HR-009). The inclusion criteria were as follows: (1) age below 16 years; (2) final height percentile measurement recorded before September 30, 2015; (3) treatment duration of 2-12 months; and (4) presented at the Aijoa clinic for treatment for height gain. The exclusion criteria were as follows: (1) missing record of dependent variables; (2) history of GH deficiency; and (3) outliers, predefined by height percentile value less than the mean 
percentile by more than three times the SD.

\section{Predictive Variables for Height Gain}

The height and weight of the patients were recorded at baseline as well as at the end of herbal medicine treatment for height gain. Body mass index (BMI) was calculated using the electronic medical record (EMR) system. Data regarding sex, age, expression of secondary sex characteristics, and previous medical history including $\mathrm{KM}$ and $\mathrm{GH}$ treatment were obtained from the medical records of the patients. Midparental target height (MPH) was calculated automatically using the EMR system, according to the formula [Predicted height of a boy $=$ (father's height + mother's height +13$) / 2$; Predicted height of a girl $=($ father's height + mother's height -13$) / 2]^{16)}$. Chronological age (CA) was also calculated automatically. All of the children who presented for treatment for height gain were referred to a external medicine clinic for the evaluation of bone age (BA) and Cobb's angle using diagnostic X-ray equipment (REX-320R; Listem, Seoul, Korea $)^{17}$. Bone age was evaluated based on the anteroposterior(AP) view X-ray images of the left hand and wrist, according to the Greulich-Pyle method $^{18), 19)}$. Cobb's angle and BA were evaluated by the same radiologist.

\section{Dependent Variables and Definition of Responders}

Height percentiles were calculated automatically using the EMR system according to the standard growth chart published by the Korean Pediatric Society in 2007 based on the results of a nationwide research ${ }^{20)}$. Since the height percentiles were published on a monthly basis, the height percentiles of the children included in our study were re-calculated every month using the well-established modified LMS algorithm ${ }^{20), 21)}$.
Percentiles were measured at baseline and at the end of herbal medicine therapy for height gain. The difference in height percentile before and after treatment was defined as the primary outcome variable. In secondary analysis, children with the upper and lower one-third values of differences in percentile before and after treatment were categorized into the responder and non-responder groups, respectively. Upon division of the tertile groups, in cases where the lowest percentile values of the upper group and the highest percentile values of the lower group exhibited similar values, all of the unique percentile values were included in the analysis.

\section{Therapeutic Intervention}

Individualized herbal medicine in the form of water-extract decoction $(60 \mathrm{~mL}$; twice a day) was prescribed to each patient on the basis of pattern identification. The composition of the prescribed herbal medicine and treatment duration were also recorded. Treatment duration was defined as the number of prescribed herbal medicine packages divided by two, since every patient was instructed to ingest two packages of herbal medicine per day. Since treatment for rhinitis or obesity is often performed in conjunction with treatment for height gain, the usage of major medicinal herbs that treat obesity, such as Ephedra sinica, and rhinitis, such as Forsythiae fructus and Schizonepeta tenuifolia, was recorded in order to investigate the effects of these additional medicinal herbs on treatment response.

Herbal formula prescribed to each child was defined as the formula prescribed for more than $30 \%$ of the total treatment duration. The names of the herbal formulas have been presented in Table 5, along with the 'methods of treatment (治法)' according to traditional Chinese medicine theory. Description of the "methods of treatment' followed the World Health Organization 
international standard terminologies on traditional medicine ${ }^{22)}$.

\section{Statistical Analysis}

Statistical analysis was performed using SPSS 18.0 for Windows (SPSS Inc., Chicago, IL, USA). While continuous variables among the baseline characteristics were expressed as mean values $\pm \mathrm{SD}$, minimum values, $25^{\text {th }}$ percentiles, $75^{\text {th }}$ percentiles, and maximum values, binary variables were expressed frequencies and percentages. The influence of each predictive variable on a dependent variable was evaluated by simple linear regression analysis. Predictive variables that exhibited p-values $<0.2$ upon simple linear regression analysis were further evaluated by multiple linear regression analysis. The predictive variable for inclusion in the final model was selected using the stepwise regression method. Values of $p<0.05$ were considered statistically significant. The $\mathrm{R}^{2}$ and adjusted- $\mathrm{R}^{2}$ values were also calculated. The optimal cutoff value for the prediction of response to treatment was determined by ROC curve analysis of the continuous variable that was included in the final model. The cutoff value was calculated according to the Youden index, which maximizes the sum of sensitivity and specificity ${ }^{23)}$.

The feasibility of the regression model was verified by the following method. Autocorrelation was evaluated using the Durbin-Watson index; values between 1.8 and 2.2 indicated the absence of autocorrelation ${ }^{24), 25)}$. Multicollinearity was determined according to the variance inflation factor (VIF); values $>10$ indicated multicollinearity ${ }^{26)}$. In case of variables with VIF $>$ 10 , the variable with the highest VIF was excluded from multiple linear regression analysis. The normality of distribution of the residuals was evaluated by the Kolmogorov-Smirnov analysis, where, $\mathrm{p}$-value $>0.1$ indicated normality. The homoscedasticity of the residuals was qualitatively evaluated using graphs.

\section{Results}

\section{Basic Characteristics of the Patients}

A total of 5,439 patients presented at the clinic, among whom, 93 visited for treatment for height gain and underwent measurement for height percentile at baseline and at the end of treatment. Of the 93 patients, only 61 (male, $\mathrm{n}=25$; mean age, $10.7 \pm 2.4$ years) satisfied the inclusion and exclusion criteria. Of the 61 patients, 3 had previously received KM therapy, while 1 had received GH therapy. The other basic characteristics of the patients are shown in Table 1.

\section{Simple Linear Regression Analysis}

In order to avoid multicollinearity, the representative variables were included in regression analysis. For example, height and weight were integrated into the BMI index. In simple linear regression, the p-values for sex, age, expression of secondary sex characteristics, MPH, BMI, CA minus BA, and administration of Forsythiae fructus and Schizonepeta tenuifolia were less than 0.2 (Table 2). Therefore, these eight variables were further analyzed by multiple regression analysis.

\section{Multiple Linear Regression Analysis}

None of the variables exhibited autocorrelation and multicollinearity. Assumptions of normality and homoscedasticity of the residuals were satisfied. Upon multiple linear regression analysis by stepwise selection, patient age and administration of Forsythiae Fructus were revealed to be the only two variables included in the final model. The regression model was found to be statistically significant. The adjusted- $\mathrm{R}^{2}$ value was 0.231 (Table 3). The regression equation of difference in percentile was as follows:

Difference in percentile before and after treatment $=6.032+0.42 *$ usage of Forsythiae fructus (days)

$-0.607 *$ age (year) 
Table 1. Baseline Characteristics of the Patients Included in This Study $(n=61)$

\begin{tabular}{|c|c|c|c|c|c|}
\hline Variable & $\begin{array}{c}\text { Frequency, } \\
\mathrm{n}(\%) \text { or Mean } \pm \mathrm{SD}\end{array}$ & Minimum value & $25^{\text {th }}$ percentile & $75^{\text {th }}$ percentile & Maximum value \\
\hline Sex (Male) & $25(41.0 \%)$ & - & - & - & - \\
\hline (Female) & $36(59.0 \%)$ & & & & \\
\hline $\begin{array}{l}\text { Expression of secondary sex } \\
\text { characteristics }\end{array}$ & $23(27.7 \%)$ & - & - & - & - \\
\hline Previous KM therapy & $3(4.9 \%)$ & - & - & - & - \\
\hline Previous GH therapy & $1(1.6 \%)$ & - & - & - & - \\
\hline Age, year & $10.7 \pm 2.4$ & 5.3 & 9.0 & 12.3 & 15.8 \\
\hline Height, $\mathrm{cm}$ & $141.1 \pm 15.5$ & 103.4 & 129.7 & 152 & 173.4 \\
\hline $\mathrm{MPH}, \mathrm{cm}$ & $163.7 \pm 6.7$ & 154.0 & 158.5 & 169.5 & 179.5 \\
\hline Height percentile, $\%$ & $47.0 \pm 29.9$ & 0.1 & 18.5 & 76.0 & 98.0 \\
\hline Weight, kg & $39.2 \pm 14.2$ & 16.3 & 27.7 & 50.1 & 83.0 \\
\hline Body mass index, $\mathrm{kg} / \mathrm{m}^{2}$ & $19.0 \pm 3.7$ & 13.8 & 16.3 & 20.9 & 32.2 \\
\hline Bone age, months & $131.3 \pm 32.6$ & 59 & 108 & 157 & 192 \\
\hline Cobb's angle, degrees & $2.7 \pm 4.5$ & 0 & 0 & 6.5 & 15 \\
\hline Treatment duration, days & $105.2 \pm 53.5$ & 60 & 60 & 120 & 255 \\
\hline $\begin{array}{l}\text { Difference in height percentile } \\
\text { before and after treatment }\end{array}$ & $-.72 \pm 4.87$ & -13 & -2.50 & 3 & 14 \\
\hline
\end{tabular}

Continuous values are expressed in terms of mean value \pm standard deviation. Binary variables are expressed in terms of frequency and ratio (\%). $\mathrm{GH}$, growth hormone; KM, Korean Medicine; MPH, midparental target height; SD, standard deviation.

Table 2. Results of Simple Linear Regression Analysis

\begin{tabular}{|c|c|c|c|c|c|c|c|c|}
\hline \multirow[t]{2}{*}{ Variable } & \multicolumn{2}{|c|}{$\begin{array}{l}\text { Unstandardized } \\
\text { Coefficient }\end{array}$} & \multirow{2}{*}{$\begin{array}{c}\text { Standardized } \\
\text { Coefficient } \\
\beta \\
\end{array}$} & \multirow[b]{2}{*}{$\mathrm{t}$} & \multirow[b]{2}{*}{$\operatorname{Adj} . R^{2}$} & \multirow[b]{2}{*}{ p-value } & \multicolumn{2}{|c|}{$\begin{array}{c}\text { 95\% Confidence Interval for } \\
\text { B }\end{array}$} \\
\hline & $\mathrm{B}$ & Standard Error & & & & & Lower limit & Upper limit \\
\hline Sex & 1.900 & 1.254 & .194 & 1.515 & .021 & $.135^{*}$ & -.609 & 4.409 \\
\hline Age, year & -.710 & .248 & -.349 & -2.859 & .107 & $.006^{*}$ & -1.207 & -.213 \\
\hline Secondary sex characteristics & -2.484 & 1.256 & -.249 & -1.977 & .046 & $.053^{*}$ & -4.998 & .030 \\
\hline $\mathrm{MPH}, \mathrm{cm}$ & -.122 & .093 & -.168 & -1.312 & .012 & $.194 *$ & -.307 & .064 \\
\hline Height percentile, $\%$ & -.013 & .021 & -.077 & -.593 & -.011 & .555 & -.055 & .030 \\
\hline Body mass index, $\mathrm{kg} / \mathrm{m}^{2}$ & -.331 & .167 & -.250 & -1.985 & .047 & $.052 *$ & -.665 & .003 \\
\hline CA minus BA, month & .089 & .067 & .171 & 1.333 & .013 & $.188 *$ & -.045 & .222 \\
\hline Cobb's angle, degrees & .044 & .139 & .042 & .319 & -.015 & .751 & -.234 & .323 \\
\hline Before KM therapy & 2.046 & 2.895 & .092 & .707 & -.008 & .482 & -3.747 & 7.839 \\
\hline Before GH therapy & 4.350 & 4.918 & .114 & .884 & -.004 & .380 & -5.491 & 14.191 \\
\hline Treatment duration, days & -.002 & .012 & -.020 & -.153 & -.017 & .879 & -.026 & .022 \\
\hline $\begin{array}{l}\text { Administration of Ephedra } \\
\text { sinica, days }\end{array}$ & -.002 & .011 & -.028 & -.212 & -.016 & .833 & -.025 & .020 \\
\hline $\begin{array}{l}\text { Administration of Forsythiae } \\
\text { fructus, days }\end{array}$ & .046 & .013 & .412 & 3.473 & .156 & $.001 *$ & .020 & .073 \\
\hline $\begin{array}{l}\text { Administration of } \\
\text { Schizonepeta tenuifolia, days }\end{array}$ & .032 & .009 & .407 & 3.419 & .151 & $.001 *$ & .013 & .051 \\
\hline
\end{tabular}

*p-value $<0.2$ (included in multiple linear regression analysis)

Adj.R², adjusted R-square; BA, bone age; CA, chronological age; GH, growth hormone; KM, Korean Medicine; MPH, midparental target height. 
Table 3. Results of Multiple Linear Regression Analysis

\begin{tabular}{|c|c|c|c|c|c|c|c|c|}
\hline \multirow[t]{2}{*}{ Variable } & \multicolumn{2}{|c|}{ Unstandardized Coefficient } & \multirow{2}{*}{$\begin{array}{c}\text { Standardized } \\
\text { Coefficient }\end{array}$} & \multirow[b]{2}{*}{$\mathrm{R}^{2}$} & \multirow[b]{2}{*}{ Adj. $R^{2}$} & \multirow[b]{2}{*}{$\Delta \mathrm{R}^{2}$} & \multirow[b]{2}{*}{$\mathrm{F}$} & \multirow[b]{2}{*}{ p-value } \\
\hline & B & Standard error & & & & & & \\
\hline Constant & 6.032 & 2.628 & & & & & & \\
\hline $\begin{array}{l}\text { Administration of Forsythiae } \\
\text { fructus, days }\end{array}$ & .042 & .013 & .371 & .170 & .156 & & 12.062 & .002 \\
\hline Age, year & -.607 & .233 & -.298 & .257 & .231 & .075 & 10.027 & .012 \\
\hline
\end{tabular}

Variables including sex, expression of secondary sex characteristics, predicted adult height, body mass index, difference between the chronological and bone ages, and administration of Schizonepeta tenuifolia were excluded from the model by stepwise selection. Adj. $R^{2}$, adjusted R-square.

\section{Cutoff Value of Patient Age for Prediction of Treatment Response with Herbal Medicine}

The differences in height percentile before and after treatment ranged from 3 to 14 in the responder group $(\mathrm{n}=21)$ and -13 to -1 in the non-responder group $(n=24)$. While 7 of the children in the responder group exhibited a difference in height percentile of 3,6 in the non-responder group exhibited a difference of -1 . Therefore, although the numbers of lower and upper tertiles were both greater than 20 , they were not equal. The average patient ages were $10.1 \pm 2.0$ years and $11.5 \pm 2.2$ years in the responder and non-responder groups, respectively. The difference in mean age between the two groups was statistically significant ( $p=0.023$; Figure 1). The area under curve of ROC curve (AUC) was 0.698 (95\% Confidence Interval (CI), 0.537-0.860; $\mathrm{p}<0.001)$. The optimal cutoff value of age, which exhibited maximum sensitivity (83.3\%) and specificity (61.9\%) for the prediction of response to herbal medicine treatment, was 9.75 years (Figure 2). This indicated that treatment response in children below 9.75 years of age was better compared to that in children older than 9.75 years.

\section{Age-Related Differences in Treatment Response}

Based on the cutoff value of age, we performed

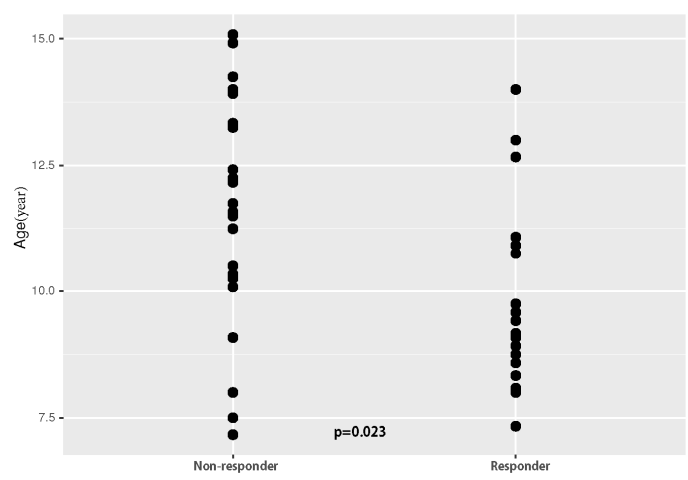

Fig. 1. Comparison of age distribution between the non-responder $(n=24)$ and responder $(n=21)$ groups

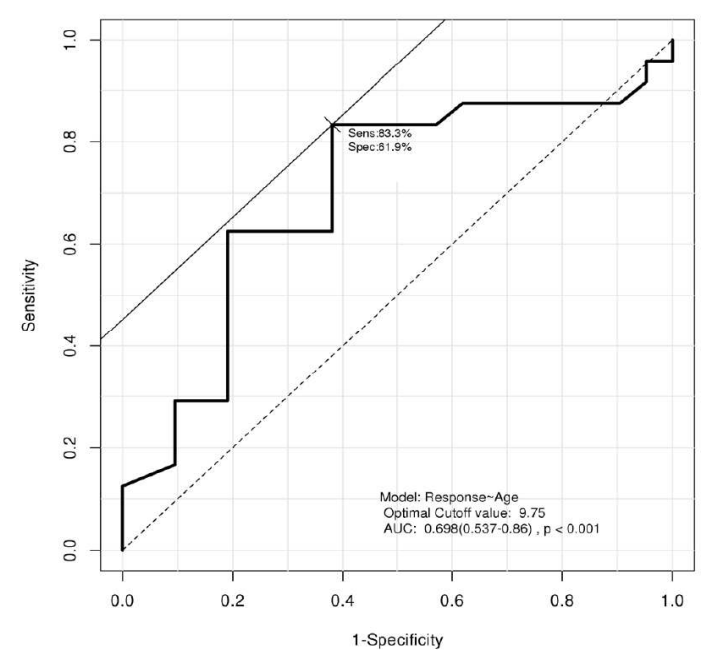

Fig. 2. Receiver operating characteristic curve of the optimal age for treatment response AUC, Area Under the Curve; Sens, Sensitivity; Spec, Specificity 
subgroup analysis in order to identify any age-related differences in treatment response. Analysis of covariance (ANCOVA) was performed for comparison of variables between the younger (age $\leq 9.75$ years) and older (age $>9.75$ years) groups of children. The baseline and post-treatment height percentiles were the covariate and dependent variables, respectively. Normality of distribution was confirmed by the Kolmogorov-Smirnov test $(p>0.05)$, and equality of variance was satisfied by Levene's test $(p>0.05)$. The interaction term between the baseline percentile and age was not significant. Therefore, this interaction term was excluded in the final ANCOVA. Before adjustment for the baseline percentile, the height percentile was increased in the younger group (49.61-53.00), but decreased in the older group (45.47-44.58) of children. According to the results of ANCOVA after adjustment for the baseline percentile, the post-treatment height percentile was significantly higher in the younger group compared to that in the older group ( $<<0.001$; Table 4$)$.

\section{Method of treatment and herbal formula for height gain in each child}

The dryness-moistening (潤燥劑) and tonifying and replenishing (補益劑) formulas are the most frequently used treatment methods for height gain in children. The most frequently prescribed herbal formula in the present study was modified Jaeumyangyeongtang (滋陰 養榮湯加減方), which was administered to 26 children. Detailed method of treatment and herbal formula for height gain in each child are shown in Table 5. Detailed composition of each herbal formula is presented in supplementary 1. Modified formula indicates " $a$ formula derived from the original one with some addition or reduction of ingredients" ${ }^{22)}$, according to traditional East Asian medicine (TEAM) theory. To elaborate, depending on the symptoms of the children, some medicinal herbs were added or removed from the herbal formulas presented in supplementary 1. For example, if a child presented with rhinitis, Forsythiae fructus and Schizonepeta tenuifolia were added to the herbal formula based on the judgment of the physician.

\section{Discussion}

\section{Summary of the Main Findings}

The results of the present study showed that the age of initiation of herbal medicine treatment and administration of Forsythiae fructus are predictive factors for treatment response for height gain in children. The optimal cutoff value of age for the prediction of treatment response with herbal medicine was 9.75 years, which indicated that the children of the younger age group exhibited better treatment response than the

Table 4. Comparison of Height Percentiles Before and After Treatment Between the Younger and Older Age Groups, Adjusted According to the Baseline Height Percentile, by ANCOVA

\begin{tabular}{|c|c|c|c|c|c|c|c|c|}
\hline \multirow[t]{2}{*}{ Group } & \multicolumn{2}{|c|}{$\begin{array}{l}\text { Height percentile } \\
\text { before treatment }\end{array}$} & \multicolumn{2}{|c|}{$\begin{array}{c}\text { Height percentile } \\
\text { after treatment }\end{array}$} & \multicolumn{2}{|c|}{$\begin{array}{c}\text { Estimated height } \\
\text { percentile after treatment }\end{array}$} & \multirow[b]{2}{*}{$\mathrm{F}$} & \multirow[b]{2}{*}{ p-value } \\
\hline & Mean & SD & Mean & SD & Mean & SE & & \\
\hline $\begin{array}{l}\text { Younger age group } \\
(\mathrm{n}=23)\end{array}$ & 49.61 & 31.17 & 53.00 & 32.30 & 50.46 & .93 & 13.744 & $\mathrm{p}<0.001$ \\
\hline $\begin{array}{l}\text { Older age group } \\
(\mathrm{n}=38)\end{array}$ & 45.47 & 29.41 & 44.58 & 28.35 & 46.11 & .72 & & \\
\hline
\end{tabular}

The covariate is the height percentile before treatment. The patients are divided into the younger (age $<9.75$ years) and older (age $>9.75$ years) age groups.

ANCOVA, analysis of covariance; SD, standard deviation; SE, standard error. 
Table 5. Method of Treatment and Herbal Formula for Height Gain in Each Child

\begin{tabular}{|c|c|}
\hline $\begin{array}{l}\text { Treatment method } \\
\text { (number of children per treatment method) }\end{array}$ & $\begin{array}{l}\text { Herbal formula for height gain in each child } \\
\text { (number of children per herbal formula) }\end{array}$ \\
\hline Dryness-moistening formula (潤燥劑; $\mathrm{n}=32$ ) & $\begin{array}{l}\text { Jaeumyangyeongtang(滋陰養榮湯; } \mathrm{n}=26 \text { ) } \\
\text { Saenghyeolyunbueum (生血潤膚飲; } \mathrm{n}=6 \text { ) }\end{array}$ \\
\hline Tonifying and replenishing formula (補谷劑; $n=17$ ) & $\begin{array}{l}\text { Yukmijihwangwon (六味地黃元; } \mathrm{n}=6 \text { ) } \\
\text { Bojungikgitang (補中益氣湯; } \mathrm{n}=4 \text { ) } \\
\text { Bopyeagyosan (補肺阿膠散; } \mathrm{n}=2 \text { ) } \\
\text { Saengjinbohyeoltang (生津補血湯; } \mathrm{n}=2 \text { ) } \\
\text { Palmulgunjatang (八物君子湯; } \mathrm{n}=2 \text { ) } \\
\text { Nokyongdaebotang (鹿茸大補湯; } ;=1 \text { ) }\end{array}$ \\
\hline Phlegm-dispelling formula (社痰劑; $n=12$ ) & $\begin{array}{l}\text { Jowiseungcheongtang(調胃升淸湯; } \mathrm{n}=11) \\
\text { Cheongpyehwadamjeon (清肺化痰煎; } \mathrm{n}=1 \text { ) }\end{array}$ \\
\hline Digestant formula (消食劑; $\mathrm{n}=8$ ) & $\begin{array}{l}\text { Hyangsapyeongwisan and Gwakyangjeonggisan combined formula } \\
\text { (香砂本胃散 合藿香正氣散; } \mathrm{n}=5 \text { ) } \\
\text { Pyeongwisan (本胃散; } \mathrm{n}=2 \text { ) } \\
\text { Hyangsayukgunjatang (香砂六君子湯; } \mathrm{n}=1 \text { ) }\end{array}$ \\
\hline Exterior-releasing formula (解表劑; $\mathrm{n}=8$ ) & 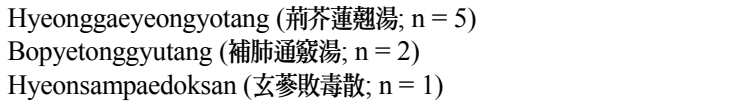 \\
\hline Tranquillizing formula (安神劑; $\mathrm{n}=4$ ) & $\begin{array}{l}\text { Gwiinansimtang (歸仁安心湯; } \mathrm{n}=2 \text { ) } \\
\text { Gwibiondamtang (歸脾溫膽湯; } \mathrm{n}=2 \text { ) }\end{array}$ \\
\hline
\end{tabular}

Herbal formula prescribed to each child was defined as the formula prescribed for more than $30 \%$ of the total treatment duration. Therefore, the total number of herbal formulas exceeds 61 .

children of the older age group. In GH treatment, a previous study attempted to identify the determinants of treatment response by multiple regression analysis ${ }^{14}$. The importance of the findings of our study lies in the fact that we were able to identify the determinants of response to herbal medicine treatment for height gain in children by multiple regression analysis by adjusting for confounding factors; to our knowledge, the present study is the first such attempt in herbal medicine treatment. Thus, the findings of our study might help guide herbal medicine treatment and clinical assessment.

\section{Interpretation of the Findings}

Several factors are predictive for adult height, including genetic factors (i.e., MPH), malnutrition, systemic disease, and environmental effects ${ }^{21), 27,28)}$. The predictors of GH treatment are the dosage of GH, MPH, delayed bone aging, height and weight at birth, age of initiation of therapy, rate of growth in the first year of birth, BMI, and baseline level of insulin-like growth factor $\mathrm{I}^{2,13), 29-31)}$. In our study, although the occurrence of secondary sex characteristics was not found to affect treatment response, patient age was an important predictive factor. In previous studies, the effect of age on treatment response with herbal medicine was a matter of controversy ${ }^{7), 9}$. However, since neither study adjusted for confounding factors, the results of the present study might be more reliable in comparison. Additionally, patient age was reported as an important predictor of GH therapy response ${ }^{2,30), 31)}$. In Korea, the ages of onset of puberty in boys and girls were reported to be $12.1 \pm 1.5$ years and $11.3 \pm 1.3$ years, respectively ${ }^{32)}$. The results of subgroup analysis in the present study revealed a significant increase in height percentile in the younger age group, but not in the older age group. Additionally, herbal medicine treatment for height gain was more effective in children below 9.75 years than in those older than 9.75 years, according to our results of ANCOVA. Therefore, we recommend the initiation 
of herbal medicine therapy at as young an age as possible during the pre-pubescent period, in order to increase the treatment response. However, this result should not be generalized as implying that herbal medicine is ineffective for height gain in older children without considering alternative explanations for the discrepancy in results between the younger and older age groups, such as small sample size, administration of various herbal medicine, and subgrouping of responders.

Treatment for rhinitis was also an important factor in predicting treatment response. At our clinic, we prescribe herbal medicine containing Forsythiae fructus or Schizonepeta tenuifolia for the treatment of rhinitis. A previous study reported that $22 \%$ of the children who presented at a $\mathrm{KM}$ hospital were affected by rhinitis ${ }^{15}$. The prevalence of rhinitis among students in general elementary schools during the last 12 months in an urban area of Korea was reported to be about $39 \%\left(95 \%\right.$ CI, 36.2-41.8) ${ }^{33)}$. It is known that rhinitis interferes with quality of sleep ${ }^{34), 35)}$. Longer duration of rhinitis and symptoms of severe rhinitis are correlated with lower sleep quality and lower height percentile ${ }^{36,37)}$. The proportion of children of short stature among a group of children with allergic diseases was reported as being high ${ }^{38)}$. Therefore, Lee et al. suggested that the impairment of GH release caused by sleep disorders in children with rhinitis leads to decreased rates of height gain $^{37}$. The effect of Forsythiae fructus on growth has not yet been investigated. Forsythiae fructus is usually prescribed for the treatment of rhinitis. Therefore, it may be speculated that the effect of treatment of rhinitis by Forsythiae fructus resulted in enhanced quality of sleep and affected the treatment response for height gain in the present study. Further studies are required to prove this hypothesis.

The results of multiple regression analysis revealed no associations between several independent variables and treatment response. However, because of the lack of statistical power, the negative results of the present study should be interpreted with caution. Heredity are important predictors of growth and $\mathrm{GH}$ treatment response $^{13), 21)}$. However, MPH was not found to be a predictor of response to herbal medicine treatment in the present study; this is in agreement with the results of previous studies on herbal medicine, which reported no influence of heredity on treatment response ${ }^{6,7)}$. The baseline height percentile was also not found to be a predictor of treatment response in the present study. However, whether baseline percentile is a determinant of treatment response with herbal medicine is a matter of controversy ${ }^{6-9}$. In a previous study, GH therapy was reported as being effective in children of the lower percentile group ${ }^{30)}$. Therefore, further investigation regarding the influence of baseline height percentile on treatment response with herbal medicine is required. The administration of Ephedra sinica, which is frequently prescribed for the treatment of obesity ${ }^{39), 40}$, was not found to influence treatment response. Additionally, because of the small proportion of children with a history of previous therapy, we were unable to evaluate the influence of previous $\mathrm{KM}$ or GH therapy on treatment response in the present study.

Treatment duration was not found to affect the treatment response. Previous studies have reported contradictory results regarding the same ${ }^{6), 9}$. In clinical practice, physicians tend to prescribe herbal medicine for longer durations for patients exhibiting poor treatment response. In cases where the treatment response is determined to be good enough, the treatment duration might be relatively shorter. Therefore, the results of the present study should not be interpreted as indicating the lack of influence of treatment duration on the rate of height gain. This hypothesis may be further verified in a retrospective study by comparison of the influence of treatment duration on the rate of height gain between similar groups using an appropriate 
matching method. And mean treatment duration of our research was relatively short (105 days) in height growth treatment. Therefore, when interpreting the relationship between treatment duration and treatment response, careful interpretation is necessary using the results of a longer period of treatment.

In the present study, several treatment methods were adopted for height growth, with the dryness-moistening formula (潤燥劑) being the most frequently administered. It is composed of several moistening medicinal herbs used for treatments of conditions of dryness and fluid deficiency ${ }^{22)}$. In TEAM, 'Yin' is associated with body fluid or structure. 'Yin deficiency' causes a decrease in moisture, which leads to dryness of the body. The dryness-moistening formula restores moisture lost because of 'Yin deficiency', causing body fluid or structures to be replenished, thus enhancing height gain. The tonifying and replenishing formula (補益劑) is used to nourish blood or replenish $\mathrm{qi}^{222}$. Both these treatment methods target the deficiency syndrome, which is an important factor in growth treatment in children ${ }^{15}$. The phlegm-dispelling formula (祛痰劑) is used for dissipating or expelling phlegm. Phlegm is defined as a pathological product accumulated in the body, which causes several diseases ${ }^{22}$. Several medicinal herbs are used to remove phlegm accumulated in the body. In the present study, Ephedra sinica was administered for weight loss, especially in obese children. Although the influence of herbal formulas for obesity treatment on height growth in children is not well established, it is an interesting subject for further research. The digestant formula (消食劑) is used to enhance digestion and disperse stagnant food ${ }^{22}$. Herbal medicine treatment for digestive problems is known to aid height growth in children ${ }^{8)}$. Sleep disorders due to chronic rhinitis interferes with growth in children ${ }^{37)}$. The tranquillizing formula (安神劑) is used to relieve mental stress and stabilize the mind to improve sleep quality ${ }^{22)}$. The exterior-releasing formula (解表劑) is used to discharge pathogenic factors from superficial parts of the body such as the nose or skin. ${ }^{22}$. In our study, several exterior-releasing formulas were used to treat rhinitis.

\section{Limitations and Implications for Future Research}

There are several limitations of our retrospective review. First, the weight and height at birth and the prevalence of atopic diseases were not investigated as potential predictors in this study. In order to address this issue, such variables should be investigated in future studies. Second, in the present study, because of the lack of data on the follow-up BA, the difference in height percentile between baseline and post-treatment was evaluated as the dependent variable. Although the difference in height percentile is widely used in studies on height gain using herbal medicine, the rate of height gain $(\mathrm{cm} / \text { year })^{14), 41)}$ and expected adult height, calculated based on the $\mathrm{BA}^{42)}$, according to the Bayley and Pinneau method ${ }^{43)}$, are also commonly evaluated treatment outcomes. Future studies should evaluate the BA again at the end of treatment in order to determine the expected adult height and also perform annual measurement of height in order to calculate the rate of height gain. Third, because of the small sample size, we were unable to calculate the optimal cutoff ages for the male and female patients separately. We recommend subgroup analysis with lager sample size in future studies in order to address this issue. Fourth, the negative results of the present study should be interpreted with caution considering the possibility of type II errors because of the small sample size. The predictive power of the results of our study is relatively low since other variables that might explain the variability of response between the age groups might have been missed. The final goal of our study was to construct a prediction model for herbal medicine 
treatment that could help determine the optimal treatment regimen and goals based on realistic expectations ${ }^{14)}$. Prospective long-term follow-up studies with large sample sizes are required to conclusively confirm the findings of our study. Finally, the criteria for inclusion in our study were relatively broad. We did not target specified herbal prescription or medicinal herbs. We could not identify effect of specific prescription or medicinal herbs. However, this study was the first report regarding the determinants of response to various herbal medicine treatment for height gain in children. We recommend further analysis involving a broad spectrum of patients in order to achieve a greater generalization of results. We also recommend study design about effect of specific herbal prescription or medicinal herbs on height growth.

\section{Strengths of the Study}

The present study has several strengths. Ours is the first study involving the use of multiple regression analysis for the prediction of treatment response with various herbal medicine for height gain. Consequently, the results of our study are more robust compared to those of previous studies that performed univariate analysis $^{6,7), 99,15), 37,44)}$. Determination of the cutoff value of treatment age can be helpful in the assessment of the best course of treatment in clinical practice. The relatively wide ranges of inclusion criteria and herbal medicine prescriptions allow the generalization of results of the present study. A prospective cohort study is required to conclusively confirm the feasibility of the determinants of treatment response. However, in consideration of the time and money that a prospective study would entail, retrospective chart reviews should be given precedence. The results of our study will form the basis for further studies in this area.

\section{Conclusion}

According to the results of our retrospective review, patient age and administration of Forsythiae fructus were predictive of response to herbal medicine treatment for height gain in children. The optimal cutoff value of age for the prediction of treatment response was 9.75 years. Children below 9.75 years of age exhibited a significant increase in height percentile. The results of our study will help clinicians decide on the course of treatment. Future studies with prospective design, specific inclusion criteria and herbal medicine prescriptions, evaluation of a greater number of predictive variables, and larger sample size are required. The findings of the present study will be fundamental for creating prediction models in future studies.

\section{List of Abbreviations}

ANCOVA, analyze of covariance; BA, bone age; BMI, body mass index; CA, Chronological age; EMR, electronic medical record; GH, growth hormone; IRB, institutional review board; ISS, idiopathic short stature; TEAM, traditional East Asian medicine; KM, Korean medicine; MPH, midparental height; ROC, receiver operating curve; $\mathrm{SD}$, standard deviation; VIF, variance inflation factor

\section{Competing Interests}

The authors declare that there is no conflict of interest regarding the publication of this paper

\section{Authors' Contributions}

Jungtae Leem and Junhee Lee planned the overall study protocol. Jeeyeun Kim and Kyeungsuk Suh collected the data. Jungtae Leem drafted the manuscript 
and performed statistical analysis. Jungtae Leem, Youngkwern Lim, and Kyeungsuk Suh suggested the initial concept of this research. Junhee Lee and Youngkwern Lim participated in the revision of this manuscript and held the final responsibility for the decision to submit for publication. All the authors have read and approved the final manuscript.

\section{Ethics approval and consent to participate}

The Kyung Hee University Korean Medicine Hospital institutional review board (IRB) approved this retrospective observational study (KOMCIRB-160219 -HR-009). The acquisition of informed consent form was exempted

\section{Consent for publication}

The manuscript do not include any individual person's data

\section{References}

1. Pedicelli S, Peschiaroli E, Violi E, Cianfarani S. Controversies in the Definition and Treatment of Idiopathic Short Stature (ISS). J Clin Res Pediatr Endocrinol. 2009;1(3):105-115. doi:10.4008/ jcrpe.v1i3.53.

2. Deodati A, Cianfarani S. Impact of growth hormone therapy on adult height of children with idiopathic short stature: systematic review. BMJ. 2011;342: c7157. doi:10.1136/bmj.c7157.

3. Lee KH. Growth Hormone Therapy in Short Stature Children. J Korean Med Assoc. 2008;51(9): 849-855.

4. Souza FM, Collett-Solberg PF. Adverse effects of growth hormone replacement therapy in children. Arq Bras Endocrinol Metabol. 2011;55(8):559-565.

5. Park MJ, Kang YJ, Kim DH. Dissatisfactioin with height and weight, and attempts at height gain and weight control in Korean school-children. $J$ Pediatr Endocrinol Metab JPEM. 2003;16(4): 545-554.

6. Yu H, Min S, Kim J, Kim K. Effects to the Growth after Administration of Seongjangbojunggeonatang. $J$ Pediatr Korean Med. 2009;23(2):103-115.

7. Lee Y, Baek J, Ko M, Seo J. Herbal Medicine Promotes Growth of Children. $J$ Pediatr Korean Med. 2011;25(1):49-62.

8. Ko M, Baek J, Kim S. The Effect of Herbal Medicine to Treat Digestive System Problem on the Children's Growth. J Pediatr Korean Med. 2013;27(4):50-56.

9. Hong H, Lee J, Kim D. Analysis of Factors Enhancing Growth Effect of Boyangsungjang-Tang. J Pediatr Korean Med. 2012;26(2):62-71.

10. Kyung JS, Yu S, Lee S-Y, Gok S. A Study of Side Effects from Korean Herb Medicine on Children. J Pediatr Korean Med. 2010;24(3): 33-42.

11. Yoon H, Lee J, Kon KD. A Study for the Parent's Recognition of the Oriental Medical Treatment and the Expectation of Children's Growth. $J$ Pediatr Korean Med. 2011;25(1):119-127.

12. Park E, Lee J, Kim D. A Study for Satisfaction and Expectation of Effect on the Growth of Children Treated with Herbal Medicine. $J$ Pediatr Korean Med. 2010;24(1):36-45.

13. Ranke MB, Lindberg A, Price DA, Darendeliler F, Albertsson-Wikland K, Wilton P, et al. Age at growth hormone therapy start and first-year responsiveness to growth hormone are major determinants of height outcome in idiopathic short stature. Horm Res. 2007;68(2):53-62. doi:10.1159/ 000098707.

14. Ranke MB, Lindberg A, Chatelain $\mathrm{P}$, Wilton $\mathrm{P}$, Cutfield W, Albertsson-Wikland $\mathrm{K}$, et al. Derivation and validation of a mathematical model 
for predicting the response to exogenous recombinant human growth hormone (GH) in prepubertal children with idiopathic GH deficiency. KIGS International Board. Kabi Pharmacia International Growth Study. J Clin Endocrinol Metab. 1999;84(4):1174-1183. doi:10. 1210/jcem. 84.4.5634.

15. Han KH, Park E, Lee H. A classificatory study about the tendency of the patient who visited Oriental Medical Hospital for growth treatment. $J$ Pediatr Korean Med. 2006;20(3):161-169.

16. Jung HH, Shim KS. The Influences of Herbal Medicines as a Growth-promoting Complimentary Therapy on Predicted Adult Heights of Children. Ann Pediatirc Endocrinol Metab. 2008;13(2): 172-176.

17. Kim H, Kim HS, Moon ES, Yoon CS, Chung TS, Song HT, et al. Scoliosis imaging: what radiologists should know. Radiogr Rev Publ Radiol Soc N Am Inc. 2010;30(7):1823-1842. doi:10.1148/ rg.307105061.

18. Greulich WW, Pyle SI. Radiographic Atlas of Skeletal Development of the Hand and Wrist. 2nd ed. Stanford, California: Stanford university press. 1959.

19. Lim YK, Min SR, Hur KW, Kim HM, Chun SY, Suh KS, et al. Relationship between Bone Age, Chronological Age, Anthropometric Parameters, and Diagnosed Pulse Rate on secondary sexual character development of child-Adolescence. $J$ Korean Med. 2014;35(1): 88-98.

20. Korea Center for Disease Control and Prevention, The Korean Pediatric Soceity, The Committee for the Development of Growth Standard for Korean Children and Adolescents. 2007 Korean children and adolescents growth standard (commentary for the development of 2007 growth chart). In: Seoul: [Government report online]. Seoul: Division of Chronic Disease Surveillance; 2007:18-19, 81-92. http://www.cdc.go.kr/.
21. Choi M, Kim D, Lee J. Effect of Genetic and Environmental Factors on Growth. J Pediatr Korean Med. 2010;24(3):138-149.

22. WHO International Standard Terminologies on Traditional Medicine in the Western Pacific Region. World Health Organization, Western Pacific Region; 2007.

23. Kumar R, Indrayan A. Receiver operating characteristic (ROC) curve for medical researchers. Indian Pediatr. 2011;48(4):277-287.

24. Durbin J, Watson GS. Testing for serial correlation in least squares regression. I. Biometrika. 1950;37(3-4):409-428.

25. Durbin J, Watson GS. Testing for serial correlation in least squares regression. II. Biometrika. 1951;38(1-2):159-178.

26. Hocking RR, Pendleton OJ. The regression dilemma. Commun Stat - Theory Methods. 1983; 12(5):497-527. doi:10.1080/03610928308828477.

27. Wright CM, Cheetham TD. The strengths and limitations of parental heights as a predictor of attained height. Arch Dis Child. 1999;81(3): 257-260.

28. Modan-Moses D, Yaroslavsky A, Kochavi B, Toledano A, Segev S, Balawi F, et al. Linear Growth and Final Height Characteristics in Adolescent Females with Anorexia Nervosa. PLoS ONE. 2012;7(9). doi:10.1371/journal.pone. 0045504.

29. Kriström B, Dahlgren J, Niklasson A, Nierop AFM, Albertsson-Wikland K. The first-year growth response to growth hormone treatment predicts the long-term prepubertal growth response in children. BMC Med Inform Decis Mak. 2009;9:1. doi:10.1186/1472-6947-9-1.

30. Lee PA, Germak J, Gut R, Khutoryansky N, Ross J. Identification of factors associated with good response to growth hormone therapy in children with short stature: results from the ANSWER Program®. Int J Pediatr Endocrinol. 2011;2011:6. doi:10.1186/1687-9856-2011-6. 
31. Lee PA, Sävendahl L, Oliver I, Tauber M, Blankenstein O, Ross J, et al. Comparison of response to 2-years' growth hormone treatment in children with isolated growth hormone deficiency, born small for gestational age, idiopathic short stature, or multiple pituitary hormone deficiency: combined results from two large observational studies. Int J Pediatr Endocrinol. 2012;2012(1):22. doi:10.1186/1687-9856-2012-22.

32. Park MJ, Lee IS, Shin EK, Joung HJ, Cho SI. The timing of sexual maturation and secular trends of menarchial age in Korean adolescents. Korean $J$ Pediatr. 2006;49(6):610-616.

33. Kwon JW, Seo JH, Yu JH, Kim BJ, Kim HB, Lee SY, et al. Relationship between the Prevalence of Allergic Rhinitis and Allergen Sensitization in Children of Songpa Area, Seoul. Allergy Asthma Respir Dis. 2011;21(1): 47-55.

34. Poachanukoon O, Kitcharoensakkul M. Snoring and sleep problems in children with and without allergic rhinitis: a case control study. J Med Assoc Thail Chotmaihet Thangphaet. 2015;98 Suppl 2:S138-144.

35. Storms WW. Pharmacologic approaches to daytime and nighttime symptoms of allergic rhinitis. J Allergy Clin Immunol. 2004;114(5 Suppl):S146-153. doi:10.1016/j.jaci.2004.08.045.

36. Patwari PP. Obstructive sleep apnea syndrome is associated with delayed growth. J Pediatr. 2015; 167(1):210-211. doi:10.1016/j.jpeds.2015. 04.090.

37. Lee M, Chang G, Han Y. A Study on the Growth, Quality of Sleep of Children with Chronic Rhinitis. J Pediatr Korean Med. 2008;22(2):125-139.

38. Baum WF, Schneyer U, Lantzsch AM, Klöditz E. Delay of growth and development in children with bronchial asthma, atopic dermatitis and allergic rhinitis. Exp Clin Endocrinol Diabetes Off $J$ Ger Soc Endocrinol Ger Diabetes Assoc. 2002;110(2):53-59. doi:10.1055/s-2002-23486.
39. Kim BS, Song MY, Kim H. The anti-obesity effect of Ephedra sinica through modulation of gut microbiota in obese Korean women. $J$ Ethnopharmacol. 2014;152(3):532-539. doi:10. 1016/j.jep.2014.01.038.

40. Boozer CN, Daly PA, Homel P, Solomon JL, Blanchard D, Nasser JA, et al. Herbal ephedra/caffeine for weight loss: a 6-month randomized safety and efficacy trial. Int $J$ Obes Relat Metab Disord J Int Assoc Study Obes. 2002;26(5):593-604. doi:10.1038/sj.ijo.0802023.

41. Lee KH, Lee BC, Ko CW, Jin DK, Yang SW, Yoo HW, et al. A Single-Arm, Phase III Study to Assess Efficacy and Safety after 6-Month-Treatment of EutropinTM Inj. (Recombinant Human Growth Hormone) in Prepubertal Children with Short Stature due to Small for Gestational Age. Ann Pediatirc Endocrinol Metab. 2011;16(3):157-164.

42. Kim EJ, Lim YJ, Lee HS, Hwang JS. The Effect of Gonadotropin Releasing Hormone Agonist and Growth Hormone on Predicted Adult Height in Girls with Precocious Puberty. Ann Pediatirc Endocrinol Metab. 2007;12(2):111-118.

43. Bayley N, Pinneau SR. Tables for predicting adult height from skeletal age: revised for use with the Greulich-Pyle hand standards. J Pediatr. 1952;40(4): 423-441.

44. Lee MS, Park KW, Park JS, Kim HJ, Moon SR. Effects of nutritional supplement with herbal extract on bone mineral density and height in prepubescent children - a preliminary study. Phytother Res PTR. 2005;19(9):810-811. doi:10. 1002/ptr. 1718.

\section{ORCID}

Jungtae Leem: https://orcid.org/0000-0003-3300-5556

Junhee Lee: https://orcid.org/0000-0001-6897-2824 